\title{
Periocular corticosteroids in diabetic papillopathy
}

AM Mansour ${ }^{1,2}$, MA El-Dairi', MA Shehab ${ }^{3}$, HK Shahin', JA Shaaban² and SR Antonios ${ }^{4}$

\begin{abstract}
Purpose To ascertain the therapeutic effect of periocular corticosteroids in diabetic

papillopathy.

Methods Prospectively, five consecutive adult-onset diabetic patients with symptomatic diabetic papillopathy underwent visual fields and fluorescein angiography before and after superonasal subtenon injection of corticosteroids.

Results The median duration of papillopathy was 2.5 weeks by ophthalmoscopy and 3 weeks by fluorescein angiography. The median recovery time of best-spectaclecorrected visual acuity was 2 weeks. Two patients developed sequential diabetic papillopathy, and both reported faster visual recovery and better subjective vision in treated eyes. In these two patients, the final bestspectacle-corrected visual acuity and visual evoked responses were comparable between the two eyes, while automated visual fields were less constricted in treated eyes. Complications included ocular hypertension, mild progression of cataract, and mild ptosis in one patient each.

Conclusions Periocular corticosteroids shortened the duration of diabetic papillopathy from a reported median of 5 months to 3 weeks in the present uncontrolled observational study, partly by their angiostatic and antioedema effects at the level of the anterior optic nerve. Intraocular pressure needs to be monitored in eyes receiving periocular corticosteroids.
\end{abstract}

Eye (2005) 19, 45-51. doi:10.1038/sj.eye.6701418

Published online 16 April 2004

Keywords: diabetic papillopathy; optic neuropathy; periocular corticosteroids

\section{Introduction}

Acute disc swelling with superficial, dilated, radially oriented, fluorescein-incontinent capillaries ${ }^{1-5}$ was initially described in longstanding juvenile diabetic patients, many being asymptomatic, or having simultaneous bilateral disease. Diabetic papillopathy lasted several months, and resolved with mild to moderate visual loss. ${ }^{3,6,7}$ Periocular corticosteroids were used to treat intermediate or posterior uveitis, ${ }^{8}$ optic disc neovascularization from chronic uveitis, ${ }^{9}$ rubeosis iridis, ${ }^{10}$ cystoid macular oedema, ${ }^{11}$ and arteritic ischaemic optic neuropathy. ${ }^{12}$ We investigated the effect of periocular corticosteroids on the duration of diabetic papillopathy.

\section{Materials and methods}

Six eyes of five consecutive adult-onset diabetic patients attending a referral clinic (AMM) over a 6-month period (August 2002-January 2003) were treated for diabetic papillopathy (one patient was uniocular and four patients had bilateral disease) (Table 1). Eyes were diagnosed with diabetic papillopathy if the disc was swollen with superficial telangiectatic radial vessels, fluorescein angiography did not show delay in either onset or time to completion of prelaminar optic disc filling, a positive history of diabetes mellitus, and a negative history of temporal arteritis and pseudotumour cerebri. Treatment consisted of injecting corticosteroids ( $5 \mathrm{mg}$ betamethasone dipropionate and $2 \mathrm{mg}$ betamethasone sodium phosphate in $2 \mathrm{ml}$, Schering-Plaugh, USA) in the superonasal subtenon space. The Ethics Committee of Khoury Hospital approved the therapy that was administered after informed patient consent. The potential side effects of corticosteroid injections and the investigational nature of the therapy were thoroughly explained.
${ }^{1}$ Department of Ophthalmology American University of Beirut

Beirut, Lebanon

${ }^{2}$ Department of Anesthesiology Fouad Khoury Hospital Beirut Lebanon

${ }^{3}$ Makassed General Hospital Beirut, Lebanon

${ }^{4}$ Beirut Eye Center, Rizk Hospital Beirut, Lebanon

Correspondence:

A Mansour, MD

Department of

Ophthalmology American

University of Beirut

Beirut, Lebanon

Tel: 9611374625

Fax: 9611744464

E-mail: dr.ahmad@

cyberia.net.lb

Published online: 16 April 2004

The authors have no proprietary interest in any product mentioned in the manuscript. 


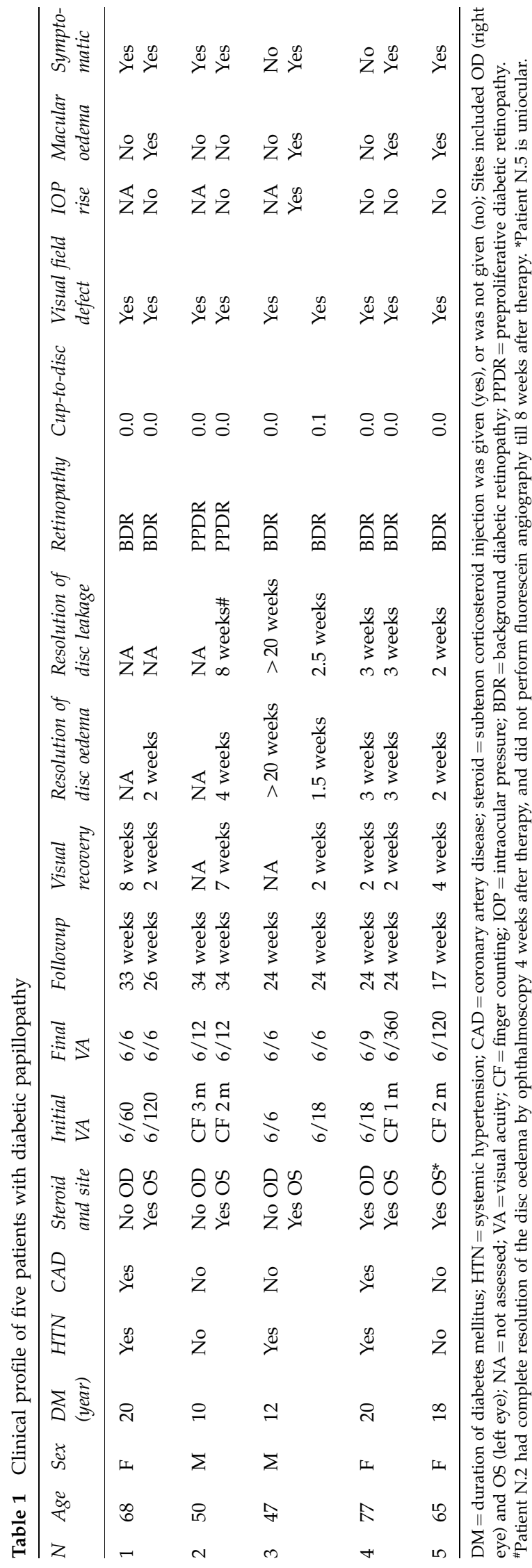

\section{Case reports}

Case 1. This 68-year-old white woman presented with sudden visual loss in the right eye. Systemic history included diabetes mellitus of 20 years, systemic hypertension, coronary artery disease, and prior coronary bypass surgery. Examination of the right eye revealed a best-spectacle-corrected visual acuity of 6/60, diffuse disc oedema and peripapillary retinal venous dilation. After 2 weeks, visual acuity improved to 6/15 with decrease in disc oedema. She developed a similar attack in the left eye 6 weeks after presentation. Bestspectacle-corrected visual acuity in the left eye was $6 / 120$. The left optic disc was elevated and hyperaemic with flat dilated superficial capillaries, peripapillary nerve fibre layer haemorrhages, and mild cystoid macular oedema. The right optic disc was pale. She consented to periocular injection of corticosteroids in the left eye. After 1 week, visual acuity improved to $6 / 9$ with marked decrease in disc oedema. At 2 weeks after injection, visual acuity in the left eye was $6 / 6$ with resolution of disc and macular oedema. The right disc was pale, small in size, and with an effaced cup. The right eye underwent periocular injection of corticosteroids for mild cystoid macular oedema. At 4 weeks after presentation, the visual acuity was $6 / 6$ bilaterally, without an afferent pupillary defect. Visual fields revealed severe constriction bilaterally more pronounced in the right eye, and decreasing after therapy in the left eye (Figure 1). Pattern visual evoked responses had comparable waveforms in both eyes (normal latency and mild attenuation of the amplitudes). Colour vision revealed mild red-green deficiency in the right eye only by $\mathrm{H}-\mathrm{R}-\mathrm{R}$ pseudo-isochromatic plates (American Optical, USA, 2d ed, 1957). There was no change in visual acuity, appearance of disc and macula, and visual fields bilaterally till the last follow-up, 7.5 months after the onset of papillopathy in the left eye.

Case 2. This 50-year-old white man with diabetes mellitus of 10 years presented with sudden visual loss in the right eye. He had an afferent pupillary defect in the right eye. The best-spectacle-corrected visual acuity was counting finger at 3 meters in the right eye and $6 / 6$ in the left eye. Funduscopy revealed marked swelling of the right optic disc, and preproliferative diabetic retinopathy changes bilaterally. He underwent panretinal laser photocoagulation to the right eye. At 2 weeks after laser, the disc oedema decreased, and visual acuity stabilized at the 6/24 level. At 7 months after initial presentation, the patient underwent panretinal laser photocoagulation to the left eye. At 2 months after laser therapy, he developed severe visual loss in the left eye to counting finger $2 \mathrm{~m}$. The left optic disc was diffusely swollen with telangiectatic vessels. He received periocular 
a
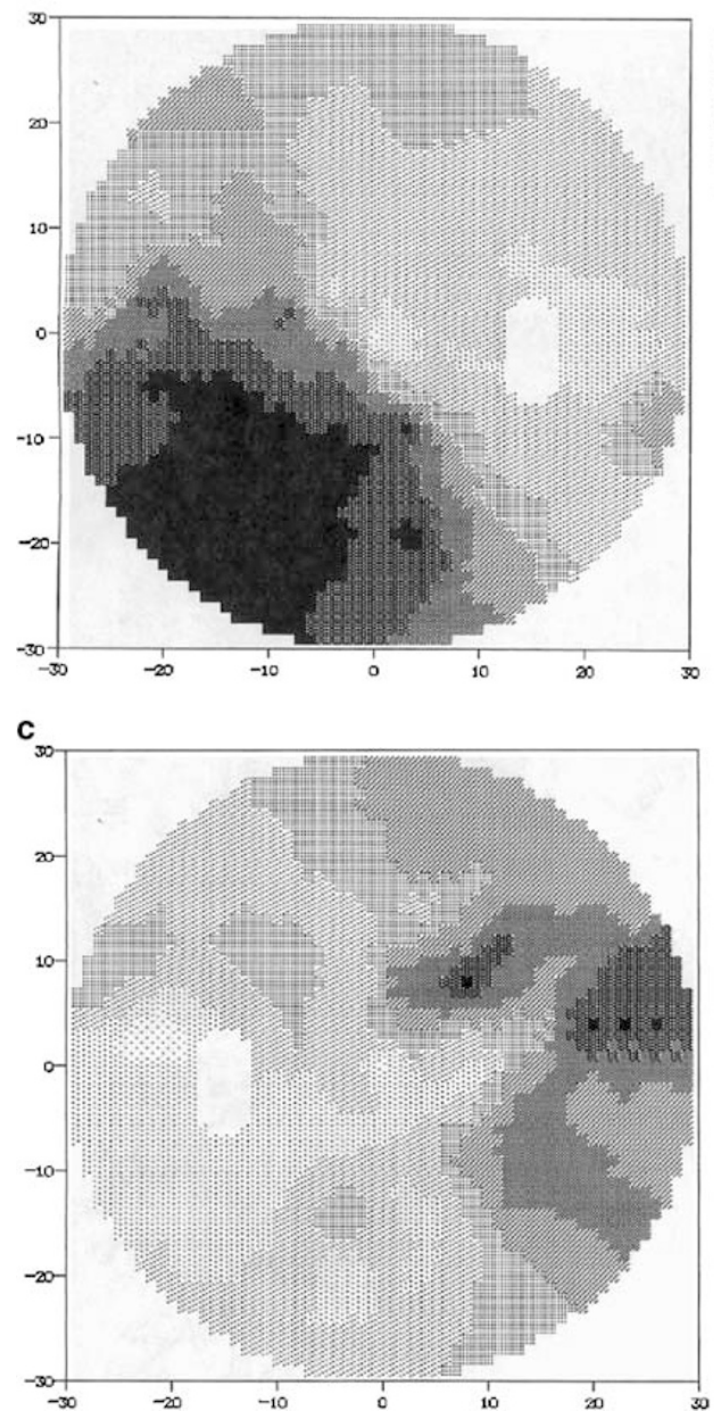

b
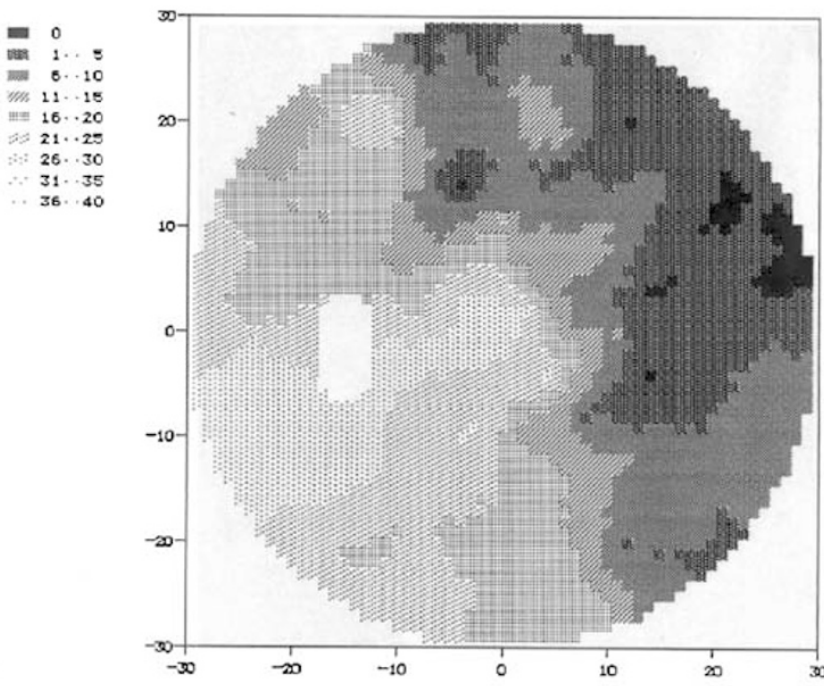

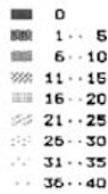

d

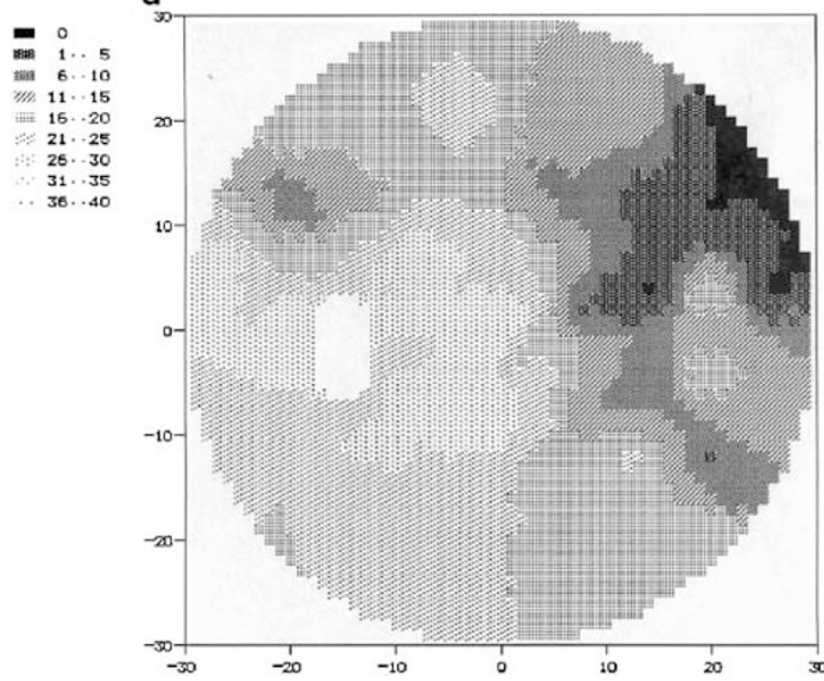

a $1 . .5$ in $5 \cdot 10$ YIM. $11 \cdots 15$ IIIII 11.20 $26 \cdots 30$ $31 \cdots 35$
$36 \cdots 40$

Figure 1 Visual fields of Case 1 in the untreated right eye (a) 9 weeks after the onset of diabetic papillopathy. Visual fields of Case 1 in the treated left eye initially (b), 2 weeks after therapy (c), and 6 months after therapy (d).

corticosteroids in the left eye. The patient reported marked visual improvement 2 weeks after injection. At 4 weeks after injection, best-spectacle-corrected visual acuity in the left eye was 6/60 with resolved disc oedema. Intravenous fluorescein angiography demonstrated an absence of disc leakage in the left eye. Macular oedema was absent bilaterally. Both discs were small in size and had an effaced cup. At 10 weeks after visual loss in the left eye, best-spectacle-corrected visual acuity was $6 / 12$ bilaterally, with a right afferent pupillary defect. Automated visual fields showed severe constriction bilaterally more pronounced in the right eye (Figure 2). Pattern visual evoked responses had comparable waveforms in both eyes (normal latency and mild attenuation of the amplitudes). Both eyes failed to recognize any colour plate using the $\mathrm{H}-\mathrm{R}-\mathrm{R}$ pseudoisochromatic plates. The optic nerve appearance, fovea, and visual fields were bilaterally unchanged 22 and 34 weeks after the onset of papillopathy in the left eye.

Case 3. This 47-year-old white man with diabetes mellitus for 12 years noted sudden visual loss in the left eye. Best-spectacle-corrected visual acuity was 6/15 in the left eye with elevation of the optic disc superiorly, background diabetic retinopathy, and a normalappearing fovea. He had a large inferior arcuate visual field defect in the left eye. Colour vision was positive for medium red-green defect bilaterally by the H-R-R pseudo-isochromatic plates. Profuse disc leakage of fluorescein dye was noted bilaterally. There was a diffuse perivascular dye leakage from dilated capillaries 
a

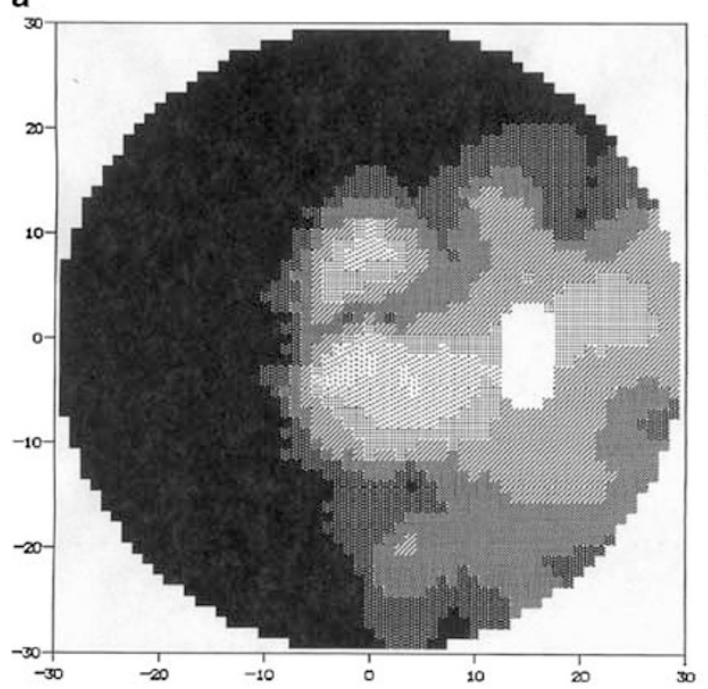

C

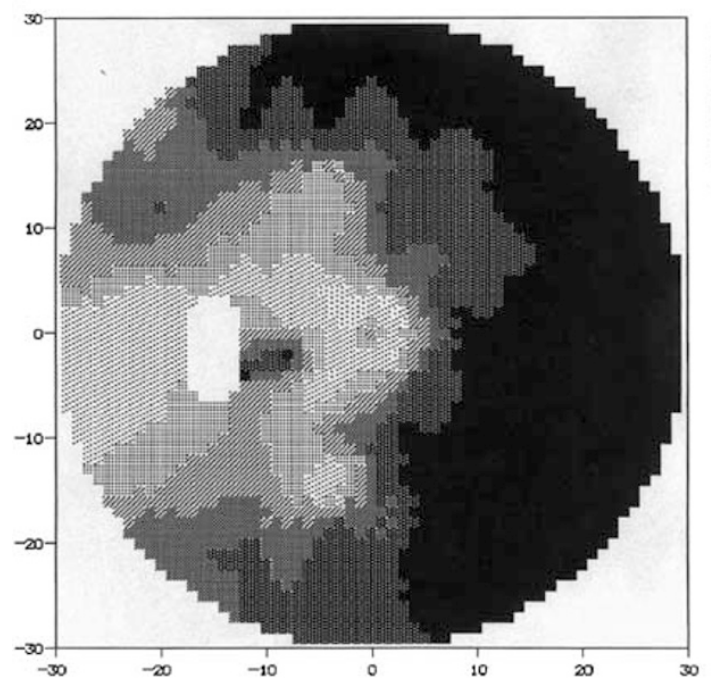

b
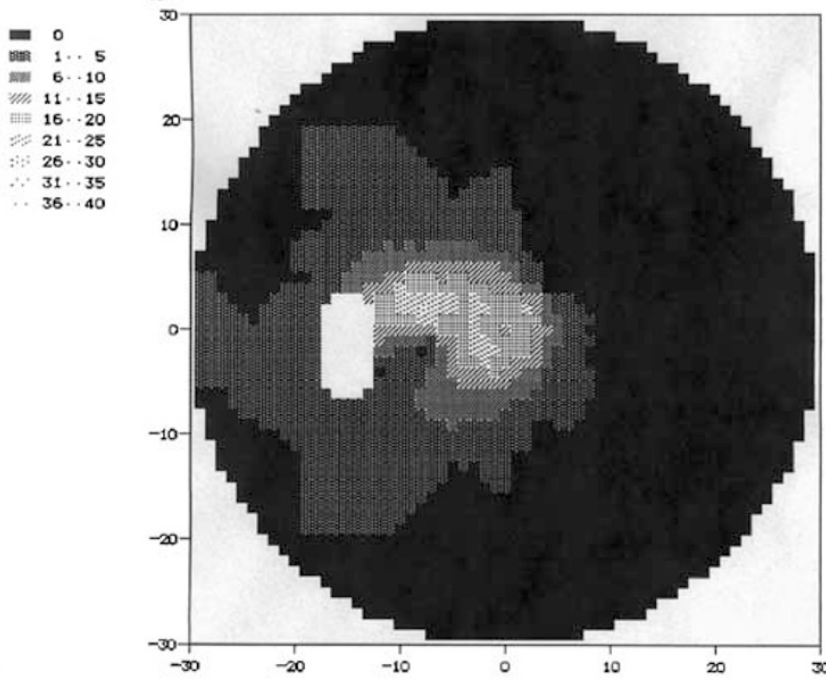

1 ins

in $6 \cdot 10$

$11 \cdots 15$
$16 \cdots 20$

$16 \cdot 20$
$21 \cdot 25$

$26 \cdot 30$
$31 \cdots 35$

$36 \cdots 40$

\section{d}

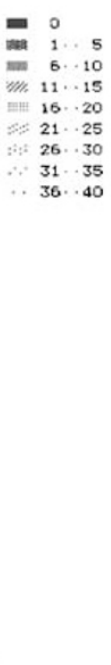

$=\begin{aligned} & 0 \\ & 1 \ldots 5\end{aligned}$ $=5 \cdots 10$ yox $11 \cdots 15$ 16.20
21.25 : $26 \cdots 30$ 26.30
$31 \cdots 35$ $31 \cdots 35$
$36 \cdots 40$

Figure 2 Visual field in the untreated right eye (a) 1 year after the acute onset of diabetic papillopathy in Case 2. Visual fields in the treated left eye initially (b), 2 weeks after therapy (c), and 6 months after therapy (d) in Case 2.

throughout the posterior pole, reminiscent of VEGF retinopathy model. ${ }^{13}$ The patient consented to periocular injection of corticosteroids in the left eye. After 5 later, best-spectacle-corrected visual acuity improved to 6/9. After 11 days later, best-spectacle-corrected visual acuity was 6/9 with resolution of disc oedema. Visual fields were unchanged. There was marked decrease in disc leakage in the left eye by fluorescein angiography. At 3 weeks after presentation, best-spectacle-corrected visual acuity was $6 / 6$ in the left eye. Intraocular tension rose to $30 \mathrm{mmHg}$, and was controlled by topical antiglaucoma medication. The status of optic disc and macula in both eyes were unchanged 20 and 24 weeks after the onset of papillopathy. Visual field defects decreased in the left eye 24 weeks after presentation. A 1-mm asymptomatic left ptosis was noted.
Case 4. This 77-year-old white woman with diabetes mellitus of 20 years noted sudden visual loss in the left eye. Best-spectacle-corrected visual acuity was 6/15 in the right eye, and finger counting $1 \mathrm{~m}$ in the left eye. The disc was swollen superiorly in both eyes. There was focal superior leakage in the right disc and diffuse severe leakage in the left disc. There was mild cystoid macular oedema in the left eye. Visual fields showed severe contraction of the central field in the left eye and superior arcuate defect in the right eye. The patient underwent bilateral periocular injection of corticosteroids. At 9 days after injection, best-spectacle-corrected visual acuity was $6 / 9$ in the right eye and finger counting $3 \mathrm{~m}$ in the left eye. Disc oedema and macular oedema decreased bilaterally. At 15 days after presentation, best-spectaclecorrected visual acuity was 6/9 and finger counting at 
$4 \mathrm{~m}$. Disk leakage decreased markedly in both eyes on repeat fluorescein angiography (Figure 3). The diffuse visual field defects decreased markedly in both eyes.
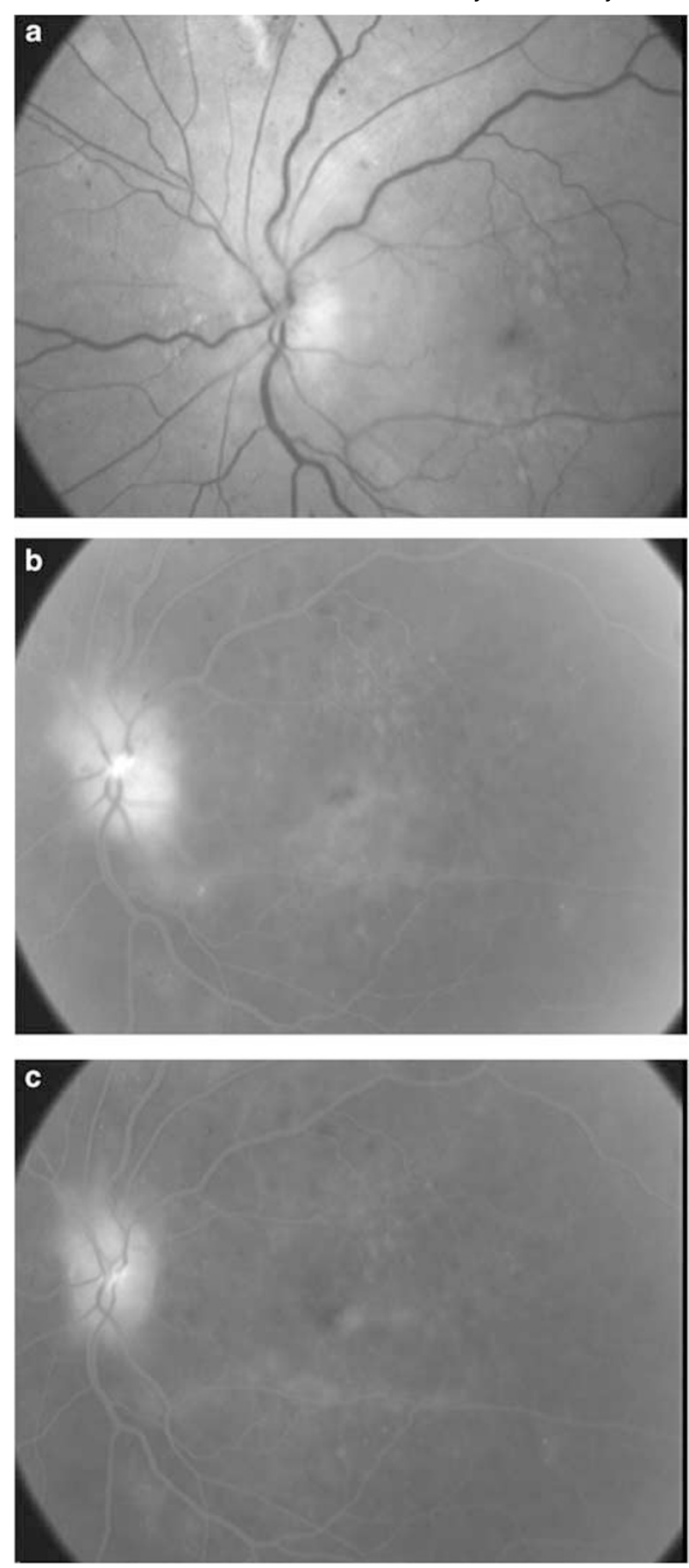

Figure 3 Posterior pole photograph of the left eye (a) in Case 4 (before therapy). During late phases of fluorescein angiography, there is profuse leakage from the abnormal capillaries of the optic disc, resulting in cystoid macular oedema (b) (before therapy). Posterior pole of the left eye in Case 4 during the late phases of fluorescein angiography, 3 weeks after therapy. Both disc and macular leakage of fluorescein have decreased markedly (c).
Posterior pole examination and visual fields were unchanged 10 and 23 weeks after presentation, with best-spectacle-corrected visual acuity of 6/360 in the left eye. Mild cataract progression was noted bilaterally 24 weeks after therapy.

Case 5. This 65-year-old uniocular white woman with diabetes mellitus of 18 years noted sudden visual loss in the left eye. Best-spectacle-corrected visual acuity was finger counting at $2 \mathrm{~m}$ in the left eye with diffuse disc oedema, cystoid macular oedema, and background diabetic retinopathy changes. She received periocular injection of corticosteroids. Fluorescein angiography showed early marked disc leakage. She had complete obliteration of central and nasal fields with islands of temporal fields remaining. At 2 weeks after injection, best-spectacle-corrected visual acuity was finger counting at $3 \mathrm{~m}$, with resolution of disc oedema, absence of disc leakage on fluorescein angiography, and improvement in central visual field. Best-spectaclecorrected visual acuity stabilized at 6/120 and visual fields were unchanged 4, 7, 14, and 17 weeks after presentation.

Summary of case reports was tabulated (Table 1). The median duration of papillopathy in treated eyes was 2.5 weeks by $90-\mathrm{D}$ slit-lamp examination, and 3 weeks by fluorescein angiography (Figure 3). Best-spectaclecorrected visual acuity was attained at a median of 2 weeks after therapy. Macular oedema resolved in all treated eyes. Visual field defects decreased in treated eyes after 2 weeks of therapy and stayed stable thereafter (Figures 1 and 2). Ocular hypertension, mild cataract progression, and asymptomatic minimal ptosis occurred, noted in one patient each.

Cases 1 and 2 had sequential papillopathy with the right untreated eye and the left treated eye. Both reported repeatedly 'seeing better' in the treated eye, and both had similar best-spectacle-corrected visual acuity in either eye, comparable pattern visual evoked responses (latency and amplitude) in either eye, but denser scotomas on visual fields in untreated eyes (Figures 1 and 2).

\section{Discussion}

Lubow and Makley ${ }^{2}$ initially described diabetic papillopathy in 1971 . Visual acuity was moderately reduced and tended to improve spontaneously. Relative pupillary defects and dyschromatopsia were atypical. ${ }^{6}$ Visual field defects included enlarged blind spots, generalized constriction, and arcuate scotomas. ${ }^{3,6,7}$ Disc oedema was often diffuse with hyperoemia. Diabetic papillopathy was considered one form of nonarteritic anterior ischaemic optic neuropathy, with special characteristics: long duration of disc oedema, mild to-moderate initial visual loss, relatively mild-to- 
moderate optic nerve dysfunction, and good visual recovery. Unlike nonarteritic ischaemic optic neuropathy ${ }_{1}^{14}$ fluorescein angiography in diabetic papillopathy does not show delay in either onset or time to completion of prelaminar optic disk filling. By combining two large series with adult-onset diabetes mellitus (51 eyes of 35 patients $^{6,7}$ ), the median duration of papillopathy was 5 months. The aetiology of diabetic papillopathy included a combination of reversible microangiopathy ${ }^{15}$ and structural factors (small disc or small cup-disc ratio). ${ }^{6}$

Several patients in the present study had poor initial visual acuity. More than $30 \%$ of reported patients with diabetic papillopathy ${ }^{3,6,7,16,17}$ (16 out of 52 patients) had initial visual acuities below or equal to $6 / 30$ as follows: two patients had $6 / 30$, eight patients had $6 / 60$, and six patients had less than $6 / 60$.

The antioedema and angiostatic effects of corticosteroids may explain the resolution of disc oedema in the present cases. Intraocular and periocular corticosteroids reduced the breakdown of blood-retinal barrier ${ }^{18}$ partly by downregulating the production of vascular permeability growth factor, also known as vascular endothelial growth factor (VEGF). ${ }^{19-22}$ Periocular corticosteroids reached the posterior segment of the eye experimentally $19,20,23,24$ and clinically. ${ }^{21,22}$ Superonasal injections allowed a high drug concentration around the optic nerve head, ${ }^{23}$ while superotemporal injections allowed a high drug concentration around the macular region. ${ }^{25}$ Early decongestion of small optic nerve head could decrease the damage to peripapillary axons and minimize subsequent optic atrophy. The rapid visual recovery in our uncontrolled observational study could have been spontaneous, unrelated to therapy. Similarly, in the two patients with sequential papillopathy, the patients' impression of better vision in the treated eye could be attributed to a placebo effect.

Macular oedema was a frequent associated finding with diabetic papillopathy, being detected in $70 \%$ of eyes. ${ }^{6}$ Macular oedema in diabetic papillopathy resulted from leakage of abnormal disc vessels. ${ }^{17}$ By stabilizing the blood-ocular barrier at the disc ${ }^{17}$ and macula (Figure 3), periocular corticosteroids resulted in resolution of macular oedema in the present case series.

Complications of periocular corticosteroids included ocular hypertension, ${ }^{26}$ cataract, ${ }^{27}$ ptosis, ${ }^{27}$ inadvertent rupture of the globe, ${ }^{28}$ systemic toxicity ${ }^{29}$ and uncontrolled hyperglyecamia. Periocular corticosteroids are not advised in eyes with chronic open-angle glaucoma and in steroid-responsive eyes. In these eyes, periocular (or intravitreal) injection of anti-VEGF EYE001 ${ }^{30}$ or angiostatic steroids (anecortave acetate, ${ }^{31}$ budesonide ${ }^{19}$ ) or bucillamine (antirheumatic drug), ${ }^{20}$ and hyperbaric therapy ${ }^{32}$ could be considered in the future.
Besides these modalities, tight blood sugar control, blood pressure regulation, anticoagulation, regular exercise, and good hydration need to be considered in the initial management of diabetic papillopathy.

\section{References}

1 Whittaker KW, Mehta JS, Tsaloumas MD. Bilateral diabetic papillopathy associated with optic disc neovascularisation. Eye 2000; 14: 914-915.

2 Lubow M, Makley TA. Pseudopapilledema of juvenile diabetes mellitus. Arch Ophthalmol 1971; 85: 417-422.

3 Barr CC, Glaser JS, Blankenship G. Acute disc swelling in juvenile diabetes. Clinical profile and natural history of 12 cases. Arch Ophthalmol 1980; 98: 2185-2192.

4 Appen R, Chandra S, Klein R, Myers F. Diabetic papillopathy. Am J Ophthalmol 1980; 90: 203-209.

5 Pavan PR, Aiello LM, Wafai MZ, Briones JC, Sebestyen JG, Bradbury MJ. Optic disc oedema in juvenile-onset diabetes. Arch Ophthalmol 1980; 98: 2193-2195.

6 Regillo CD, Brown GC, Savino PJ, Byrnes GA, Benson WE, Tasman WS et al. Diabetic papillopathy. Patient characteristics and fundus findings. Arch Ophthalmol 1995; 113: 889-895.

7 Bayraktar Z, Alacali N, Bayraktar S. Diabetic papillopathy in type II diabetic patients. Retina 2002; 22: 752-758.

8 Helm CJ, Holland GN. The effects of posterior subtenon injection of triamcinolone acetonide in patients with intermediate uveitis. Am J Ophthalmol 1995; 120: 55-64.

9 Sanislo SR, Lowder CY, Kaiser PK, Gutman FA, Zegarra H, Dodds EM et al. Corticosteroid therapy for optic disc neovascularization secondary to chronic uveitis. Am J Ophthalmol 2000; 130: 724-731.

10 Ehrenberg M, McCuen II BW, Schindler RH, Machemer R. Rubeosis iridis: preoperative iris fluorescein angiography and periocular steroids. Ophthalmology 1984; 91: 321-325.

11 Thach AB, Dugel PU, Flindall RJ, Sipperley JO, Sneed SR. A comparison of retrobulbar versus sub-tenon's corticosteroid therapy for cystoid macular oedema refractory to topical medications. Ophthalmology 1997; 104: 2003-2008.

12 Schimek RA, Newsom SR. Restoration of vision in temporal arteritis by retrobulbar injections of steroids. Am J Ophthalmol 1966; 62: 693-696.

13 Tolentino MJ, McLeod DS, Taomoto M, Otsuji T, Adamis AP, Lutty GA. Pathologic features of vascular endothelial growth factor-induced retinopathy in the nonhuman primate. Am J Ophthalmol 2002; 133: 373-385.

14 Arnold AC, Hepler RS. Fluorescein angiography in acute nonarteritic anterior ischemic optic neuropathy. $\mathrm{Am} J$ Ophthalmol 1994; 117: 222-230.

15 Inoue $M$, Tsukahara Y. Vascular optic neuropathy in diabetes mellitus. Jpn J Ophthalmol 1997; 41: 328-331.

16 Ho A, Maguire A, Yanuzzi L, Fisher Y, Galetta S, Sergott R. Rapidly progressive optic disc neovascularization after diabetic papillopathy. Am J Ophthalmol 1995; 120: 673-675.

17 Friedrich Y, Feiner M, Gawi H, Friedman Z. Diabetic papillopathy with macular star mimicking clinically significant macular oedema. Retina 2001; 21: 80-82.

18 Lee JH, Kim SJ, Chung H. The effect of subtenon injection of methylprednisolone acetate on the breakdown of blood retinal barrier after cryotherapy. Korean J Ophthalmol 1995; 9: $1-6$. 
19 Kompella UB, Bandi N, Ayalasomayajula SP. Subconjunctival nano- and microparticles sustain retinal delivery of budesonide, a corticosteroid capable of inhibiting VEGF expression. Invest Ophthalmol Vis Sci 2003; 44: 1192-1201.

20 Yanagi Y, Tamaki Y, Obata R, Muranaka K, Homma N, Matsuoka B et al. Subconjunctival administration of bucillamine suppresses choroidal neovascularization in rat. Invest Ophthalmol Vis Sci 2002; 43: 3495-3499.

21 Weijtens O, Schoemaker RC, Lentjes EGWM, Romijn FPHTM, Cohen AF, van Meurs JC. Dexamethasone concentration in the subretinal fluid after a subconjunctival injection, a peribulbar injection, or an oral dose. Ophthalmology 2000; 107: 1932-1938.

22 Weijtens O, Feron EJ, Schoemaker RC, Cohen AF, Lentjes EG, Romijn FP et al. High concentration of dexamethasone in aqueous and vitreous after subconjunctival injection. $A m$ J Ophthalmol 1999; 128: 192-197.

23 Hyndiuk RA, Reagan MG. Radioactive depot-corticosteroid penetration into monkey ocular tissue. Arch Ophthalmol 1968; 80: 499-503.

24 Kunou N, Ogura Y, Honda Y, Hyon SH, Ikada Y. Biodegradable scleral implant for controlled intraocular delivery of betamethasone phosphate. J Biomed Mater Res 2000; 51: 635-641.

25 Freeman WR, Green RL, Smith RE. Echographic localization of corticosteroids after periocular injection. Am J Ophthalmol 1987; 103: 281-288.
26 Levin DS, Han DP, Dev S, Wirostko WJ, Mieler WF, Connor TB et al. Subtenon's depot corticosteroid injections in patients with a history of corticosteroid-induced intraocular pressure elevation. Am J Ophthalmol 2002; 133: 196-202.

27 Lafranco Dafflon M, Tran VT, Guex-Crosier Y, Herbort CP. Posterior sub-Tenon's steroid injections for the treatment of posterior ocular inflammation: indications, efficacy and side effects. Graefes Arch Clin Exp Ophthalmol 1999; 237: 289-295.

28 Gopal L, Bhende M, Sharma T. Vitrectomy for accidental intraocular steroid injection. Retina 1995; 15: 295-299.

29 Ozerdem U, Levi L, Cheng L, Song MK, Scher C, Freeman WR. Systemic toxicity of topical and periocular corticosteroid therapy in an 11-year-old male with posterior uveitis. Am J Ophthalmol 2000; 130: 240-241.

30 Eyetech Study Group. Preclinical and phase 1A clinical evaluation of an anti-VEGF pegylated aptamer (EYE001) for the treatment of exudative age-related macular degeneration. Retina 2002; 22: 143-152.

31 D'Amico DJ, Goldberg MF, Hudson H, Jerdan JA, Krueger S et al. Anecortave Acetate Clinical Study Group. Anecortave acetate as monotherapy for the treatment of subfoveal lesions in patients with exudative age-related macular degeneration (AMD): interim (month 6) analysis of clinical safety and efficacy. Retina 2003; 23: 14-23.

32 Bojic L, Ivanisevic M, Gosovic G. Hyperbaric oxygen therapy in two patients with non-arteritic arterior optic neuropathy who did not respond to prednisone. Undersea Hyperb Med 2002; 29: 86-92. 